\title{
USE OF NEAR INFRARED SPECTROSCOPY FOR The Clinical Monitoring of Adult BRAIN
}

\author{
Peter J. Kirkpatrick, P. Smielewski, J. M. K. Lam, and P. Al-Rawi \\ Addenbrookes Hospital, University Department of Neurosurgery, Block A, Level 4, Hills Road, \\ Cambridge CB2 2QQ, United Kingdom \\ (Paper JBO/NIR-14 received June 18, 1996; revised manuscript received Sep. 12, 1996; accepted for publication Sep. 19, 1996)
}

\begin{abstract}
Adult near infrared spectroscopy (NIRS) is a potential method for noninvasively assessing changes in cerebral oxygenation. Unlike neonatal NIRS, access of light to the adult brain requires penetration through thick extracranial tissues, and hence detection of changes in cerebral chromophore concentration can only be achieved by using NIRS in the reflectance mode. This adds variables that are difficult to control. They include the effects of a different intraoptode distance, intersubject anatomical variation, and the influence of a pathological extra- to intracranial collateral blood supply. Although studies showing movements of oxyhemoglobin concentration following specific cerebral stimuli have been published, the separation of changes occurring in the extracranial and intracranial compartments remains a challenge. Experience with NIRS in the three adult clinical scenarios of carotid endarterectomy, head injury, and carbon dioxide stress testing is presented. The influence of extracranial contamination is demonstrated, as are the methods adopted to help control for extracranial blood flow changes. Provisional experience with spatially resolved spectroscopy (SRS) technology is also discussed. (๑) 1996 Society of Photo-Optical Instrumentation Engineers.
\end{abstract}

Keywords near infrared spectroscopy; carotid endarterectomy; carbon dioxide reactivity; head injury; multimodality monitoring, neurointensive care.

\section{INTRODUCTION}

The impetus for measuring brain oxygenation lies in the clinical significance of cerebral oxygen desaturation. Although the effects of prolonged cerebral oxygen deprivation in the neonate during birth are historically recognized, it is only recently that cerebral desaturation in adult neurointensive care has received close attention. For example, in headinjured patients, transient events of cerebral desaturation have shown a close association with a poor outcome. $^{1-3}$ The same is probably true of other coma-producing conditions, such as stroke, encephalopathies, and cerebral metabolic injury. Direct measures of cerebral oxygenation at present rely on oxygen probes (such as a Clark-type electrode) placed in the brain. ${ }^{4}$ Indirect oximetry measures the oxygen saturation of the venous effluent of the brain (jugular venous oximetry). ${ }^{2,5}$ Both techniques are labor intensive, prone to artifacts, and do not provide high spatial resolution. Thus an accurate, noninvasive, and clinically applicable method for cerebral oximetry would represent a major advance in the neurointensive care setting.

Near infrared spectroscopy (NIRS), using the principle of light attenuation by the chromophores oxy- $\left(\mathrm{HbO}_{2}\right)$ and deoxy- $(\mathrm{Hb})$ hemoglobin molecules, is a potential method for achieving noninvasive "cerebral oximetry." 6 However, passage of nearinfrared light through biological tissues is complex, and subject to several different variables. ${ }^{7}$ Of key importance is the distance the light travels as a consequence of scattering (the path-length factor of the modified Beer-Lambert law). ${ }^{6-8}$ Since near infrared light (of clinically acceptable power) can transgress the interpterional diameter of a neonatal head (transmission spectroscopy), knowledge of the path length factor allows a more direct estimation of the path length traveled. ${ }^{9-12}$ The neonatal scalp and skull tissues are relatively thin in comparison to the adult, hence the attenuation of light is probably more dependent on the concentration of relevant chromophores in cerebral tissues. Thus scalp contamination in neonatal NIRS is probably small, a factor that has contributed to the successful application of NIRS in a variety of neonatal settings. ${ }^{10-18}$

In adults, the relative thickness of scalp and brain prevent interpterional spectroscopy. Placement of the optodes on the same side of the head is necessary, and relies on light reflectance. As a consequence, nonlinear variables for light absorption and the scattering coefficient are introduced. ${ }^{19-21}$ The 
separation of the optodes necessary to reliably sample from cerebral tissues varies among individuals according to anatomical localization and differences in scalp/skull thickness. Sex and race differences are also important in that the male adult scalp and skull is thicker than in females, and the Negroid skull is thicker than non-Negroids. Finally, the method of probe application is critical. ${ }^{21}$ For example, application of probe pressure will reduce the blood content of scalp tissues, and such maneuvres may reduce the attenuation of signal by the superficial tissues in an unpredictable way. Standardization of these variables in the clinical setting is extremely difficult.

Thus, in contrast to the reproducible work carried out in neonates, adult NIRS has not enjoyed consistent enthusiasm. Concerns about scalp contamination have been vigorously voiced, with statements that some commercial NIRS machines record exclusively from extracranial tissues. ${ }^{22,23}$ Theoretical models suggesting that the depth of light penetration varies directly as a function of intraoptode distance is probably an oversimplification. With increasing intraoptode distance, the overall intensity of sampled light falls as an exponential function of this distance. Thus even if spatial resolution improves with increasing intraoptode distance, the signal-to-noise ratio decreases, and with an intraoptode distance exceeding $6.5 \mathrm{~cm}$, very little valuable signal can be detected with present commercial machines.

With these reservations in mind, clinical experience with adult NIRS is gathering, and an increasing number of well-controlled clinical publications are appearing that highlight the potential for the technique. Thus NIRS has been used to demonstrate predictable physiological changes in cerebral $\mathrm{HbO}_{2}$ and $\mathrm{Hb}$ content during respiration, ${ }^{24}$ during temporary carotid artery compression, ${ }^{25}$ external visual stimulation, ${ }^{26}$ and during cognitive stressing, ${ }^{27}$ all with high temporal resolution. The effects of extracranial changes remain a concern in studies of this type, but our experience supports the conclusion that cerebral changes in hemoglobin chromophores can be detected provided scalp changes remain relatively constant. ${ }^{28,29}$ It is the purpose of this communication to summarize previously published work using specific clinical models, the means by which we have monitored extracranial and intracranial changes in blood flow, and the incorporation of NIRS into a multimodality monitoring system employed in the adult neurointensive care unit. Our experience supports the novel concept that extracranial and intracranial contributions to signal changes detected with NIRS may in part be segregated by monitoring physiological variables specific to each compartment, rather than by attempting an anatomical resolution. Finally, our provisional experience using spatially resolved spectroscopy (SRS, Hamamatsu Ltd.) is presented.

\section{Methods}

\subsection{MULTIMODALITY MONITORING}

The adoption and coordination of a multimodality monitoring system in the Addenbrookes Neurosurgical Unit has been discussed in detail in a previous publication. ${ }^{30}$ Briefly, the system has evolved over the past 4 years to encompass the modalities of intracranial pressure (ICP), arterial blood pressure $(\mathrm{ABP})$, systemic arterial oxygen saturation using standard pulse oximetry, middle cerebral artery flow velocity (FV) using transcranial Doppler, cortical or cutaneous microcirculatory red cell flux using laser Doppler flowmetry (LDF), jugular bulb oximetry to measure cerebral venous oxygen saturation $\left(\mathrm{SjO}_{2}\right)$, and measurement of relative changes in frontal $\mathrm{HbO}_{2}$ and $\mathrm{Hb}$ with NIRS. In addition, cerebral cortical electrical activity in patients undergoing carotid surgery was monitored using a bilateral cerebral function monitor (CFM). Several or all of these parameters were used in each clinical scenario. The philosophy behind multimodality monitoring is the facility for increased power of interpretation of data, and the improved resolution for identifying the mechanisms underlying a particular cerebral event. The long-term ambition is for greater targeting of therapy.

\subsection{PRACTICAL CONSIDERATIONS FOR APPLYING NIRS}

The hardware adopted in these studies was the Hamamatsu NIR 1000 and (later) 500. Optodes were placed on the forehead and frontal scalp with an intraoptode distance of 5.0 to $6.0 \mathrm{~cm}$. One probe was sited on the forehead $2 \mathrm{~cm}$ above the supraorbital ridge and $2 \mathrm{~cm}$ from the midline away from the sagittal sinus, and the second optode was positioned high on the frontal (shaved if necessary) scalp toward the coronal suture. Specially made, light-occluding plastic caps were placed over each optode and secured with an elastic bandage. Finally, the head was bound in a lightproof drape and secured with adhesive tape. Once in place, the spectrometer was initiated and allowed to run undisturbed. Extraneous stray light causes the sensitive photomultiplier tube of the NIR 1000 to switch off automatically, preventing further data collection until the situation rectified. During long studies (e.g. monitoring head-injured patients), the probe positions require daily inspection to detect signs of evolving pressure sores, and the signals are normalized to baseline every $4 \mathrm{hr}$ to compensate for signal drift. In later studies the Hamamatsu 500 (commercial NIR) was employed and found to be easier to use, more reliable, and less sensitive to extraneous stray light. Lightproof drapes and a pressure bandage are not usually necessary with this later machine.

When combining LDF with NIRS, the overlap in light wavelength adopted by the two machines re- 


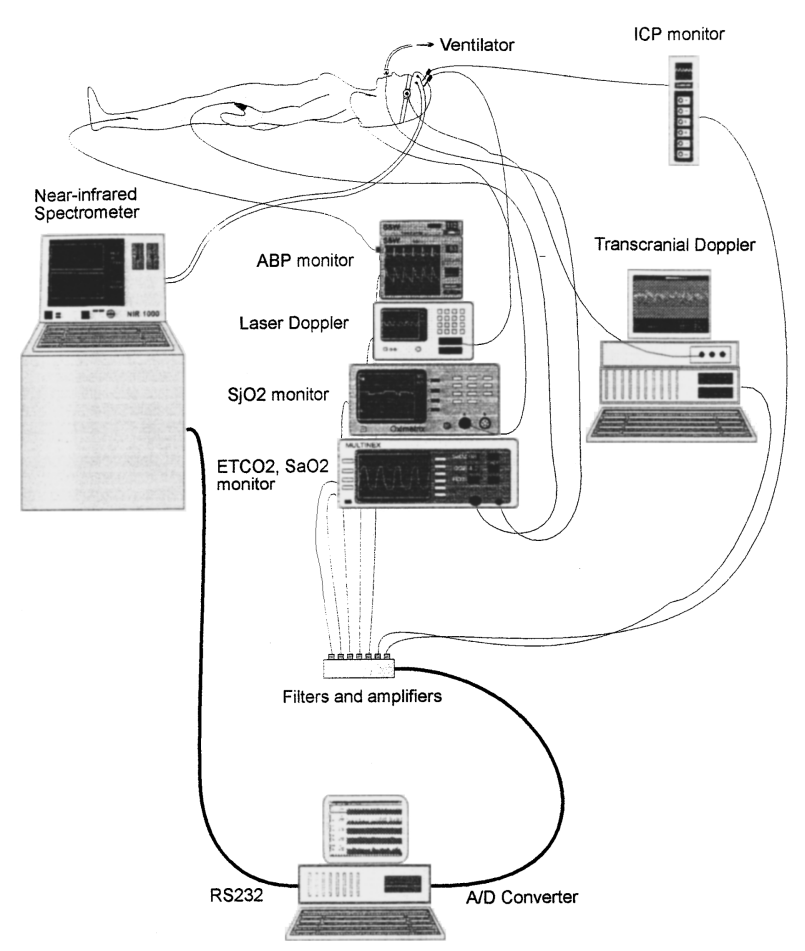

Fig. 1 Schematic drawing of the multimodality monitoring system used in the neurointensive care setting.

quires consideration. In our system, Moor's laser Doppler flowmeter (MBF3D monitor and modified P3 probe, UK) was fitted with a compatible laser diode using light in the visible spectrum.

\subsection{SIGNAL CAPTURE AND PROCESSING}

For a detailed description of technical details of signal processing, the reader is referred to Czosnyka et al. ${ }^{31}$ Briefly, signals of mean arterial blood pressure (MABP), ICP, $\mathrm{SjO}_{2}, \mathrm{SaO}_{2}, \mathrm{FV}$ and LDF were sampled (frequency $40 \mathrm{~Hz}$ ), digitized (DT 2814, Data Translation, U.S.), filtered to remove highfrequency artifacts, and averaged over consecutive 3-s epochs. MABP and ICP were calibrated in appropriate units $(\mathrm{mmHg}$ ) (Figure 1). The raw LDF signal was recorded in arbitrary units (AU). In addition, transfer of NIRS data via an RS232 was employed, and although $\mathrm{HbO}_{2}$ and $\mathrm{Hb}$ changes were initially recorded in $\mathrm{AU}$, they were subsequently converted to quantified units of micromoles/liter according to the algorithm of Cope and Delpy. ${ }^{9}$ The arithmetic sum of $\mathrm{HbO}_{2}$ and $\mathrm{Hb}$ can be calculated and expressed as total hemoglobin (THb).

Waveforms were processed using specific software. Data were stored on an IBM 386 portable PC. A minute-by-minute graphic display of mean CPP, $\mathrm{ICP}, \mathrm{LDF}, \mathrm{FV}, \mathrm{SjO}_{2}, \mathrm{HbO}_{2}$, and $\mathrm{Hb}$ was provided to assist in the clinical management of the individual patients (Figure 1).

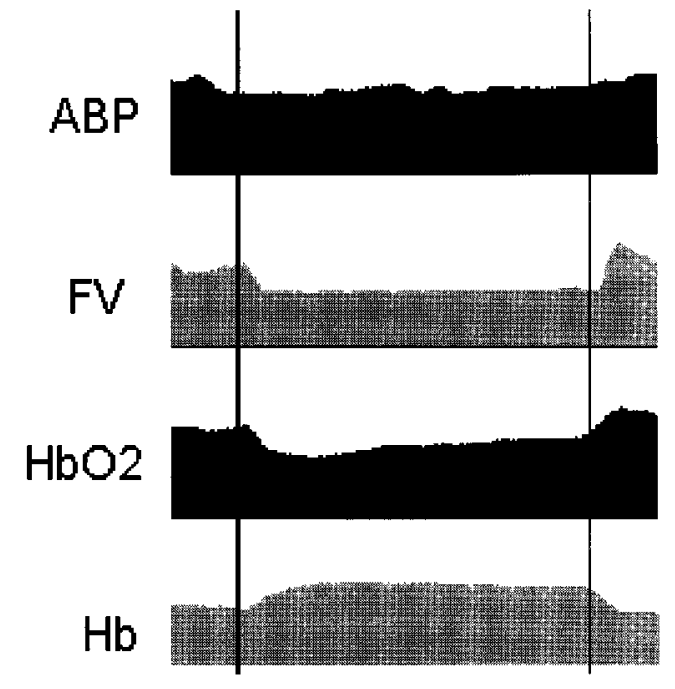

Fig. 2 Graph demonstrating the time trends of parameters monitored during carotid endarterectomy. The vertical lines indicate the times at which the internal carotid cross clamp was applied (left) and removed (right). Note the constant $A B P$, the associated fall in $\mathrm{FV}$ and $\mathrm{HbO}_{2}$ on clamp application and the reciprocal rise in $\mathrm{Hb}$, and the relative hyperemia with increased $\mathrm{FV}$ and $\mathrm{HbO}_{2}$ over baseline on reperfusion following internal carotid release. Clamp time $=22 \mathrm{~min}$. $A B P$, mean arterial blood pressure; $F V$, right middle cerebral artery flow velocity; $\mathrm{HbO}_{2}$, oxygenated hemoglobin; and $\mathrm{Hb}$, deoxygenated hemoglobin.

\section{RESUlTS AND CONCLUSIONS}

\subsection{CAROTID ENDARTERECTOMY}

A total of 101 patients undergoing carotid surgery have now been monitored using NIRS in this unit. $^{32-34}$ The operating theater presents a controlled environment for such studies with NIRS, with the patients stable under a general anesthetic. Movement artifacts are eradicated, blood pressure changes minimized, and variables such as systemic oxygenation and carbon dioxide tension are kept at constant levels for all patients.

\subsubsection{Primary Observations Using NIRS during Carotid Endarterectomy}

The first 40 patients were monitored while undergoing a standard carotid endarterectomy (CE) with clamping of the internal carotid artery (ICA), common carotid artery, and external carotid artery (ECA) in sequence. ${ }^{32}$ On application of the ICA clamp, approximately $50 \%$ of patients demonstrated a significant fall in both the $\mathrm{HbO}_{2}$ and FV signal, which was accompanied by a reciprocal rise in $\mathrm{Hb}$ (Figure 2). These events show close temporal correlation. Application of the ECA after $2 \mathrm{~min}$ did not result in any further change in these variables. At the end of the CE, reperfusion of the extracranial territory showed only minor increases in $\mathrm{HbO}_{2}$, which is usually accompanied by an increase in FV. On release of the ICA, a marked increase in $\mathrm{HbO}_{2}$ is typical, and is accompanied by hyperemia as registered by high FV. 


\subsubsection{Cerebral Desaturation during Carotid Endarterectomy}

The pooled data from 14 consecutive patients indicated that the reciprocal changes in $\mathrm{HbO}_{2}$ and $\mathrm{Hb}$ were approximately equal and opposite during stages 2 and 3 of surgery, suggesting that on average, the $\mathrm{THb}$ (and the whole blood volume assuming a constant hematocrit) remains constant at these times. ${ }^{33}$ If this is the case, then from the relationship:

Hemoglobin oxygen saturation (HbSat)

$$
=\left[\mathrm{HbO}_{2}\right] /[\mathrm{tHb}]=\left[\mathrm{HbO}_{2}\right] / \text { constant, }
$$

we would expect the $\mathrm{HbO}_{2}$ signal to vary directly with cerebral saturation. However, when $\mathrm{SjO}_{2}$ measurements were carried out in 29 consecutive patients undergoing CE with NIRS monitoring, the correlation was poor $[r=0.26$, Figure 3(a)] compared with the correlation between $\mathrm{SjO}_{2}$ and cerebral blood flow estimated by measurement of FV $[r=0.53$, Figure $3(b)]$. Either the assumptions regarding constant $\mathrm{THb}$ during $\mathrm{CE}$ were wrong, or other variables (such as extracranial contamination) were influential. Of course, it was also possible that the cortical area interrogated by NIRS did not drain exclusively into the internal jugular vein.

\subsubsection{Changing Blood Volume during Carotid Endarterectomy}

Group analysis of data can be carried out by standardizing the times of signal sampling. Thus the means for each variable were calculated over 1-min periods at specified stages of surgery. ${ }^{33}$

Stage $1=$ baseline

Stage $2=5 \mathrm{~min}$ after IC clamping

Stage $3=15 \mathrm{~min}$ after IC clamping

Stage $4=5 \mathrm{~min}$ after IC clamp release

Stage $5=15 \mathrm{~min}$ after IC clamp release.

Two distinct patterns of $\mathrm{HbO}_{2}$ change were defined [Figure 4(a)]:

Group 1 patients: the fall in $\mathrm{HbO}_{2}$ was small $(<1$ $\mu \mathrm{mol} / \mathrm{L})$ or showed a rapid recovery $(>=50 \%)$ toward baseline by stage 3 .

Group 2 patients: the $\mathrm{HbO}_{2}$ signal showed little recovery $(<50 \%)$ or continued to fall.

By stage $3, \mathrm{THb}$ was elevated above baseline in group 1 patients, and depressed below baseline in group 2 [Figure 4(b)]. Further, in group 1, a significant increase in $\mathrm{HbO}_{2}$ was seen after clamp removal (stages 4 and 5), which was not apparent in group 2.

This study indicates the significant differences occur in $\mathrm{THb}$, invalidating the assumptions underlying Eq. 1.

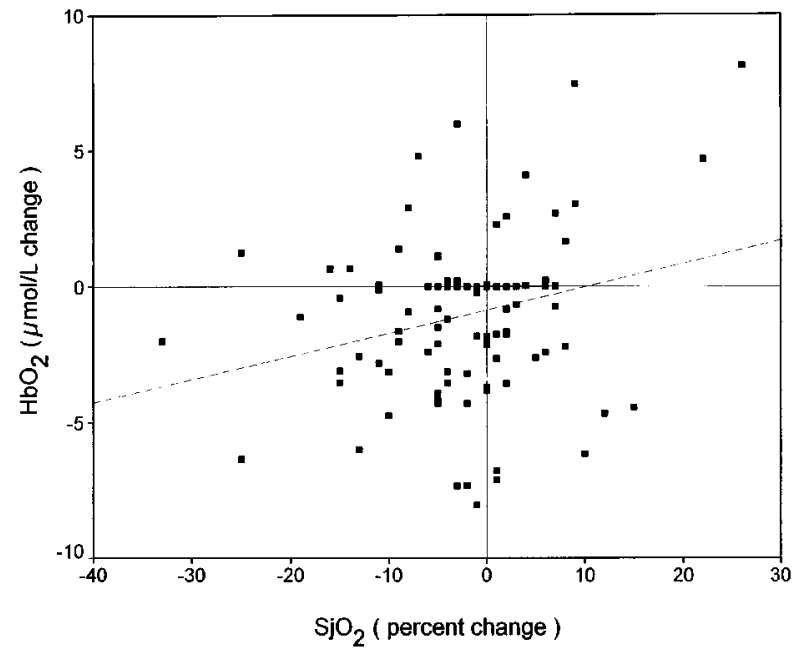

(a)

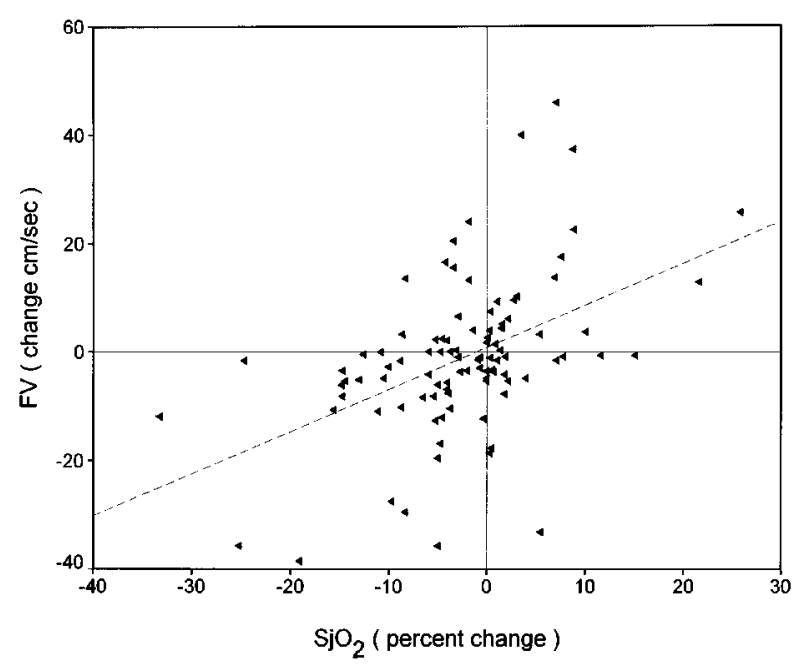

(b)

Fig. 3 (a) Correlation between $\mathrm{HbO}_{2}$ and $\mathrm{SjO}_{2}$ during carotid endarterectomy showing a poor relationship $(r=0.26$; $p=0.04)$. (b) Correlation between $\mathrm{FV}$ and $\mathrm{SjO}_{2}$ during carotid endarterectomy showing a good relationship $(r=0.53 ; p<0.01)$.

\subsubsection{Extracranial Influence on NIRS during Carotid Endarterectomy}

During surgery of the latest 43 patients, a different protocol was adopted in which the ECA was clamped for a full 2 min before ICA clamping. ${ }^{34}$ Under these surgical conditions, 34 (79\%) patients showed a fall in $\mathrm{HbO}_{2}$ on clamping the ECA, which was accompanied (except in 2 cases) by a fall in cutaneous blood flow measured with an LDF probe placed between the NIRS optodes (Table 1). On subsequent clamping of the ICA, a biexponential fall in $\mathrm{HbO}_{2}$ was seen in the majority of patients (Figure 5). In the remaining 9 cases (5 of which had severe ECA stenosis or occlusion), no NIRS changes were seen on ECA clamping. None of these had a drop in skin blood flow during the operation. Thus in patients subjected to $\mathrm{CE}$, there is frequently an extracranial component contributing to the signal 


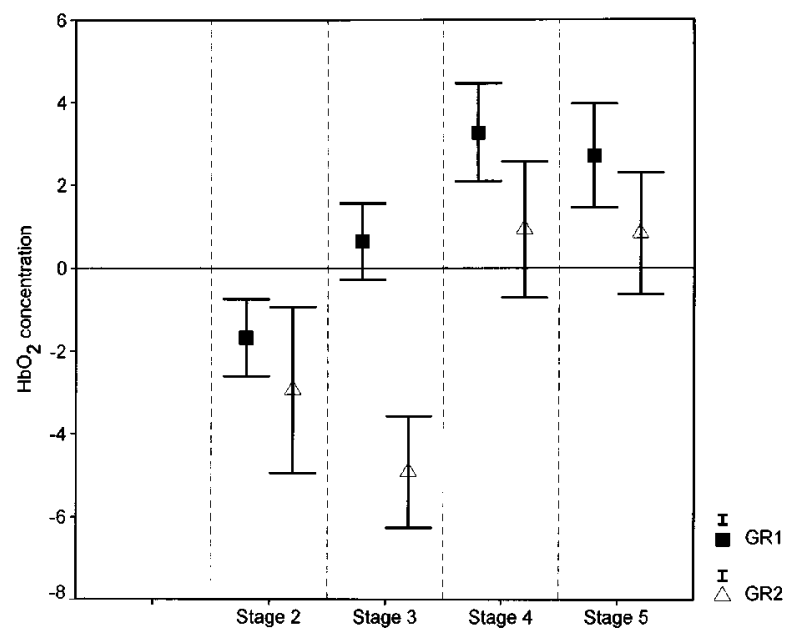

(a)

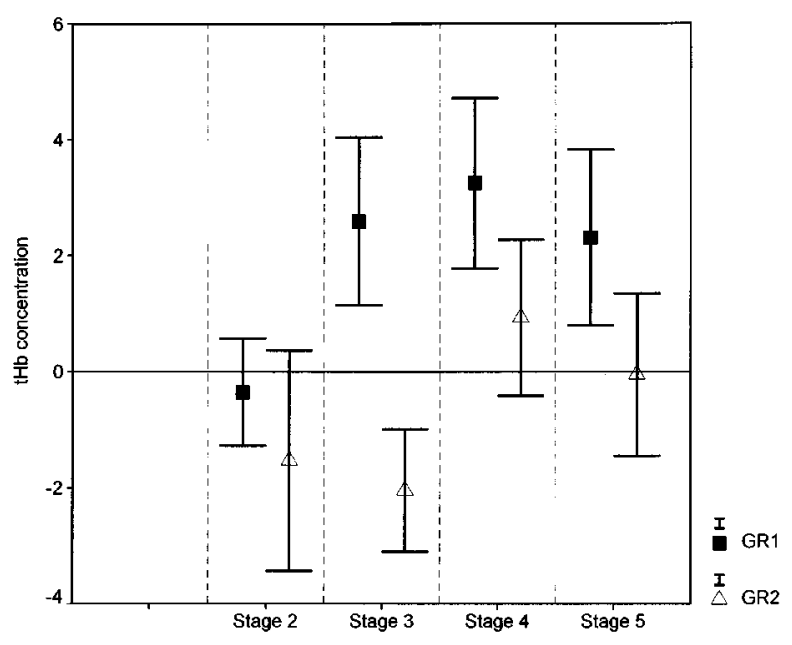

(b)

Fig. 4 (a) Variation in the behavior of the $\mathrm{HbO}_{2}$ signal changes during carotid endarterectomy. By stage 3 of surgery, group 1 patients showed a recovery to baseline values, whereas group 2 patients showed $\mathrm{HbO}_{2}$ levels below baseline. A significant increase in $\mathrm{HbO}_{2}$ levels above baseline after internal carotid (IC) clamp removal (stages 4 and 5) was seen only in group 1 patients. (b) Variation in the behavior of THb (hence cerebral blood volume) during carotid endarterectomy. By stage 3 of surgery group 1 patients showed an increase in $\mathrm{THb}$ above baseline values, whereas group 2 patients showed THb levels below baseline. In group 1 patients, the fall in $\mathrm{HbO}_{2}$ was small $(<1 \mu \mathrm{mol} / \mathrm{L}$ ) or showed a rapid recovery (>=50\%) toward baseline by stage 3 . In group 2 patients, the $\mathrm{HbO}_{2}$ signal showed little recovery $(<50 \%)$ or continued to fall. Stage 1=5 min before IC clamping; stage 2=5 min after IC clamping; stage $3=15 \mathrm{~min}$ after IC clamping; stage $4=5 \mathrm{~min}$ after IC clamp release; stage $5=15 \mathrm{~min}$ after IC clamp release.

changes during clamping. Nonetheless, when the skin component was removed, NIRS was very specific in the detection of cerebral oxygenation. Twenty-three of the 43 patients had a drop in $\mathrm{HbO}_{2}$ during ICA clamping, all of whom showed a drop in FV without skin blood flow changes (Table 1). The degree to which $\mathrm{HbO}_{2}$ fell in these patients corresponds closely to the presence of patent anterior circulation collateral flow in the circle of Willis as assessed on the preoperative digital subtraction angiograms. If the anterior communicating artery is patent, $\mathrm{HbO}_{2}$ falls to a lesser degree than in patients without cross-flow from the opposite anterior cerebral artery.

The reason extracranial contamination appeared significant during the latest carotid investigations may, besides the change in surgical protocol, reflect the prominent use of the NIR 500 in these studies. As stated in the methods, extraneous light does not affect the NIR 500 to the same extent as the NIR 1000. The use of a pressure bandage to secure the optodes was not necessary, and thus we consider that relatively greater ischemia of the underlying cutaneous tissues may have been a feature during the earlier protocol. One important assumption in these studies is that cutaneous LDF variation is representative of all extracranial blood flow changes, an assumption that awaits validation.

\subsection{HEAD-INJURED PATIENTS}

As a clinical model for assessing NIRS within a multimodality monitoring system, head-injured patients have a potential advantage over those undergoing CE. Gross manipulation of the extracranial circulation is unlikely to occur to the same extent as that following ECA clamping. ${ }^{28}$ However, the clinical environment in the intensive care setting is not as well controlled as that in operating theaters, since patient manipulation occurs regularly. Thus out of $886 \mathrm{hr}$ of continuous monitoring in 14 headinjured patients, 376 were identified who were without signal failure of any parameter. In 9 of the patients, 38 events were recorded which demonstrated clear changes in the cerebral perfusion pressure $(\mathrm{CPP}=\mathrm{ABP}-\mathrm{ICP})$ that were accompanied by cerebral hemodynamic changes in FV and cortical LDF (Figure 6). Most important, NIRS demonstrated high sensitivity and changes in 37 (97\%) events, whereas conventional $\mathrm{SjO}_{2}$ registered only 20 (53\%, Figure 7). NIRS was also capable of resolving different causes for raised ICP, such as intracranial hypoperfusion (26\%, Figure 6), systemic hypoxia $(21 \%$, Figure 7$)$, and intracranial hyperemia (21\%, Figure 8).

Although cutaneous blood flow changes were not monitored in these observational studies, the confluence of parameter changes was extremely high, and we consider it unlikely that they could be accounted for by extracranial NIRS changes only.

\subsection{CARBON DIOXIDE $\left(\mathrm{CO}_{2}\right)$ STRESS TESTING}

Normal volunteers $(n=50)$ were monitored using the multimodality methods described above. ${ }^{29,35}$ End tidal $\mathrm{CO}_{2}\left(\mathrm{EtCO}_{2}\right)$ was increased by inhalation of a mixture of $5 \% \mathrm{CO}_{2}$ in air, and decreased by means of voluntary hyperventilation; it was monitored using an infrared analyzer (Morgan Instruments, $901 \mathrm{Mk} 2$ ). The assessment consisted of $5 \mathrm{~min}$ 
Table 1 Relation between change in $\mathrm{HbO}_{2}$ and LDF during external carotid clamping.

\begin{tabular}{lccccc}
\hline & \multicolumn{2}{c}{ ECA Clamp } & & \multicolumn{2}{c}{ ICA Clamp } \\
\cline { 2 - 3 } \cline { 5 - 6 } & $\begin{array}{c}\text { Drop in } \mathrm{HbO}_{2} \\
(n=34)\end{array}$ & $\begin{array}{c}\text { No drop in } \mathrm{HbO}_{2} \\
(n=9)\end{array}$ & & $\begin{array}{c}\text { Drop in } \mathrm{HbO}_{2} \\
(n=23)\end{array}$ & $\begin{array}{c}\text { No drop in } \mathrm{HbO}_{2} \\
(n=20)\end{array}$ \\
\hline Drop in skin LDF & 27 & 0 & & 0 & 0 \\
No drop in skin LDF & 2 & 7 & & 18 & 18 \\
LDF not available & 5 & 2 & & 5 & 2 \\
\hline
\end{tabular}

of baseline recording followed by $3 \mathrm{~min}$ of hyperventilation, $5 \mathrm{~min}$ of rest, and a further $5 \mathrm{~min}$ of increased $\mathrm{CO}_{2} \cdot \mathrm{CO}_{2}$-induced cerebral vasodilation caused a linear increase in $\mathrm{CBF}$ as reflected by a rise in FV [Figure 9(a)]. There was a similar close correlation between $\mathrm{EtCO}_{2}$ and $\mathrm{HbO}_{2}$ [Figure 9(b)]. Indices for $\mathrm{CO}_{2}$ reactivity estimated using TCD and NIRS parameters are listed in Table 2.

Changes in cutaneous blood flow, assessed using cutaneous LDF, were not correlated with $\mathrm{EtCO}_{2}$ [Figure 9(c)]. Nevertheless, in some cases substantial changes in cutaneous LDF were observed during hypercapnia. This is particularly important during $\mathrm{CO}_{2}$ reactivity estimates in patients with known cerebrovascular diseases, where extra- to intracranial anastamoses become important and may introduce significant cutaneous reactivity. To estimate the contribution of cutaneous changes on $\mathrm{CO}_{2}$ reactivity measurements, we have recently introduced a maneuvre that involves a 10-s compression of the superficial temporal artery ipsilateral to the NIRS recording. Linear regression of $\mathrm{HbO}_{2}$ against LDF during the compression (assuming an LDF biological zero of 0 arbitrary units) allows an estimate of

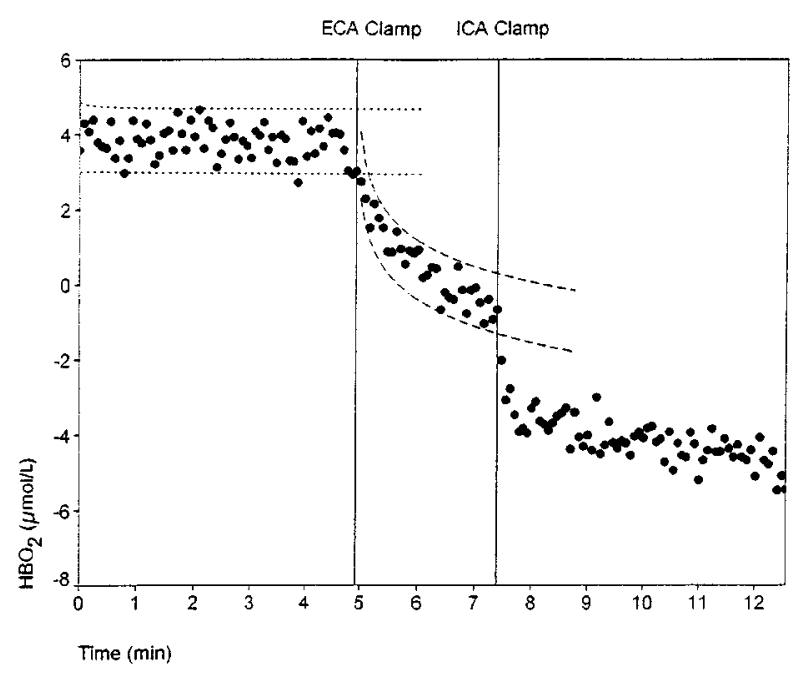

Fig. 5 Bi-exponential fall in $\mathrm{HbO}_{2}$ signal after sequential clamping of the external and (2 min later) internal carotid arteries during carotid endarterectomy. the cutaneous contribution to the $\mathrm{CO}_{2}$-induced changes in NIRS signals (see the appendix), and raises the prospect of introducing a cutaneous "correction factor." In 60 successive patients being investigated for carotid artery disease, the average skin contribution to the $\mathrm{HbO}_{2}$ reactivity index was $14 \%$, and after correction, the $\mathrm{HbO}_{2}$ reactivity indices correlated more closely with the degree of ipsilateral carotid artery stenosis (ANOVA, after correction $p=0.017$; without correction, $p=0.047$ ). Calculation of the reactivity parameter HbDiff (reactivity of $\left.\left[\mathrm{HbO}_{2}-\mathrm{Hb}\right]\right)$ improves the relationship further $(p=0.0032)$ by virtue of an increase in the signal-to-noise ratio. ${ }^{19}$

These results indicate that, in normal individuals, $\mathrm{CO}_{2}$-induced cerebral vasodilation and increased

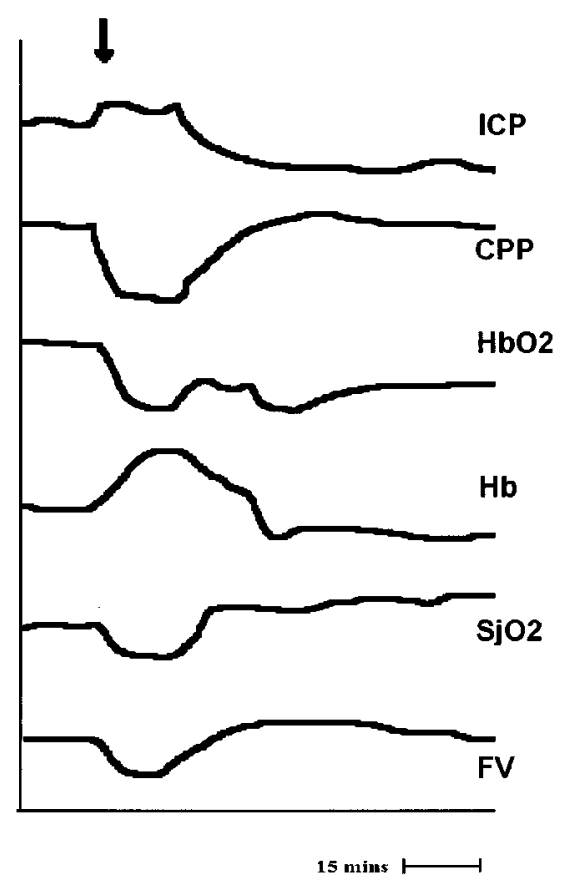

Fig. 6 A spontaneous event recorded from a head-injured patient (arrow). NIRS signals register a fall in $\mathrm{HbO}_{2}$ and reciprocal rise in $\mathrm{Hb}$ during a rise in ICP and fall in CPP (i.e., relative cerebral hypoperfusion). In this event, cerebral desaturation was confirmed by the fall in $\mathrm{SiO}_{2}$ and in relative cerebral blood flow (FV). ICP, intracranial pressure; CPP, cerebral perfusion pressure. (Adapted from P. J. Kirkpatrick et al., J. Neurosurg.) 


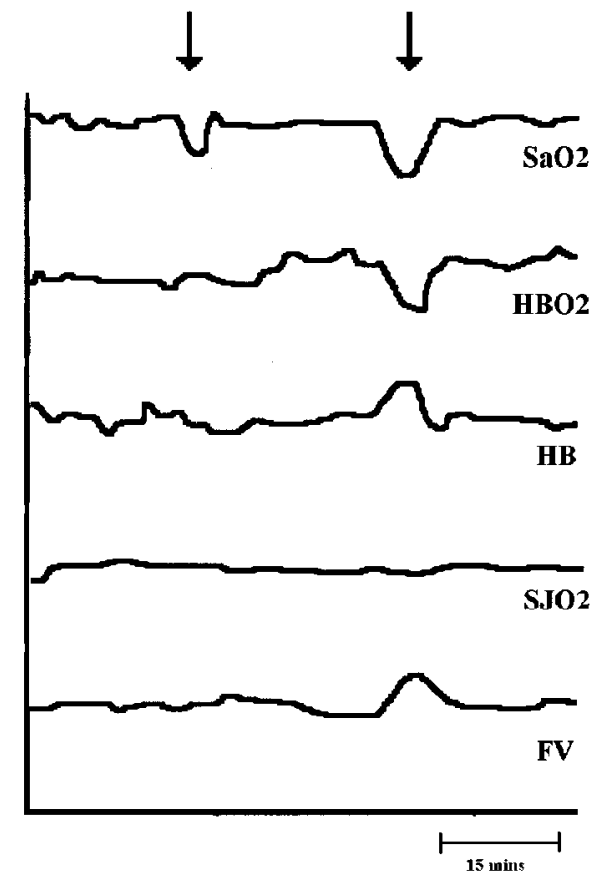

Fig. 7 Peripheral oxygen desaturation in a head-injured patient with pulmonary contusions. Two successive episodes of peripheral desaturation are shown (arrows). In the second, the fall in $\mathrm{SaO}_{2}$ is accompanied by reciprocal changes in $\mathrm{HbO}_{2}$ and $\mathrm{Hb}$, whereas the $\mathrm{SjO}_{2}$ monitor failed to register this event. (Adapted from P. J. Kirkpatrick et al., J. Neurosurg.)

$\mathrm{CBF}$ can be reliably estimated from the rise in $\mathrm{HbO}_{2}$ because extracranial changes are small. In contrast, patients with cerebrovascular disease may require correction for extracranial influences during reactivity testing, since skin flow changes become more

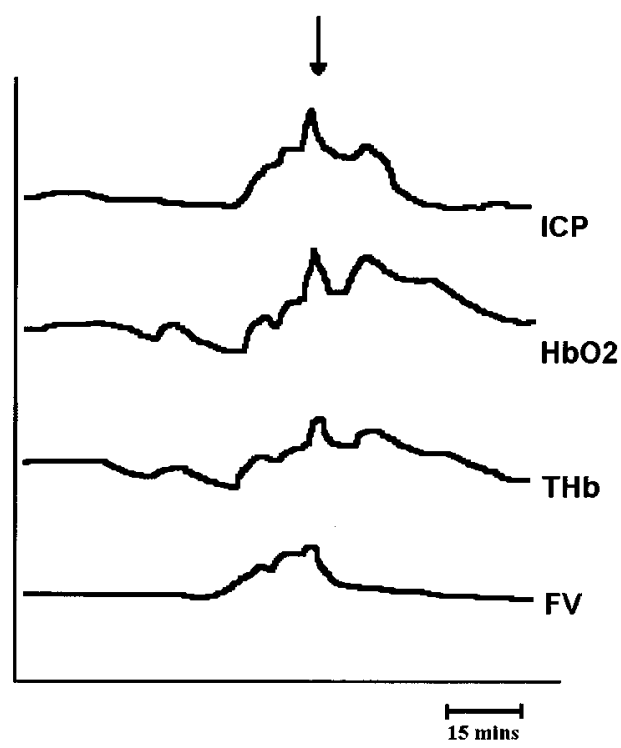

Fig. 8 Recording from a 17-year-old man suggesting cerebral hyperemia with raised FV closely associated with the increase in ICP. In this event (arrowed) synchronous and tightly correlated increases in all recorded parameters occurred which were accompanied by a relative increase in $\mathrm{THb}$ (hence cerebral blood volume). (Adapted from P. J. Kirkpatrick et al., J. Neurosurg.)
A)

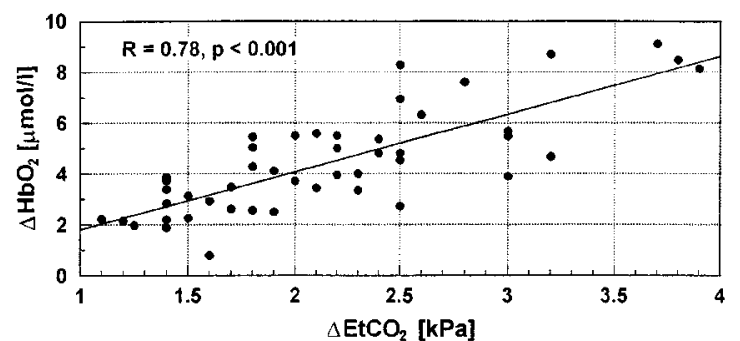

B)

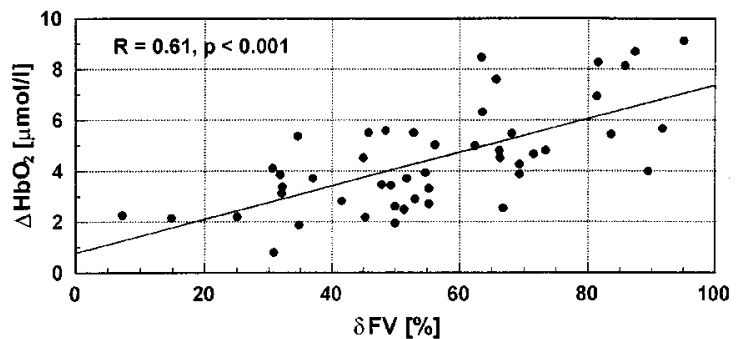

C)

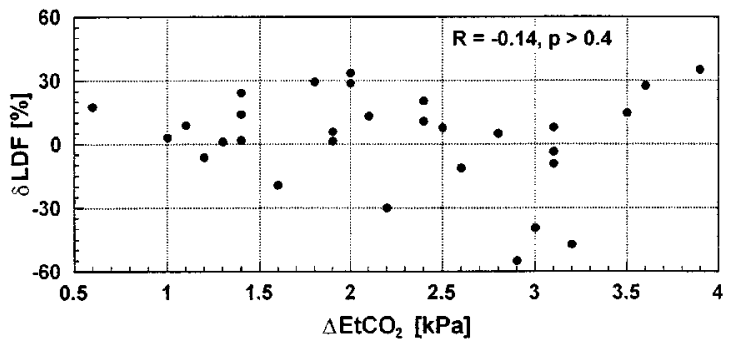

Fig. 9 (A) Scatter plot of change in $\mathrm{HbO}_{2}$ in response to changing $\mathrm{EtCO}_{2}$ in normal volunteers. (B) Scatter plot of changing $\mathrm{HbO}_{2}$ with changing $\mathrm{FV}$ during $\mathrm{CO}_{2}$ challenge in normal volunteers. (C) Relationship between cutaneous blood flow measured (with LDF) and $\mathrm{EtCO} 2$ during $\mathrm{CO}_{2}$ reactivity testing in normal individuals. $\mathrm{HbO}_{2}$, oxygenated hemoglobin levels $(\mathrm{mmol} / \mathrm{L}) ; \mathrm{EtCO}_{2}$, end tidal carbon dioxide levels $(\mathrm{kPa}) ; \mathrm{FV}$, middle cerebral artery flow velocity $(\mathrm{cm} /$ s); LDF, laser Doppler flowmetry (arbitrary units). (Adapted from P. Smielewski et al., Stroke 26, 2285-2292, 1995.)

significant. Again we make the assumption that a major component of the extracranial blood flow is within the skin, and that LDF monitoring is representative of the greater part of any extracranial changes.

\subsection{SPATIALLY RESOLVED SPECTROSCOPY (SRS)}

Hamamatsu Photonics, in conjunction with University College London, has developed the spatially resolved spectrometer, which is designed to provide a value for cerebral hemoglobin saturation. ${ }^{37}$ The SRS uses spatially resolved reflectance spectroscopy to estimate absolute concentrations of $\mathrm{HbO}_{2}$ and $\mathrm{Hb}$ from selected intracranial tissue, giving a continuous measurement for oxygen saturation. Four wavelengths of near-infrared light are delivered through a flexible fiber optic bundle housing 4 laser diodes. Back-scattered light is detected by a new design of detector which consists of 3 closely placed photodiodes arranged in 3 parallel strips. The light detected by each photodiode is used to generate a log plot of attenuation against 
Table 2 Response of mean FV and NIRS parameters to changing end tidal carbon dioxide levels $\left(\mathrm{EtCO}_{2}\right)$.

\begin{tabular}{lccccc}
\hline & $\mathrm{FV}$ & $\mathrm{HbO}_{2}$ & $\mathrm{Hb}$ & $\mathrm{H}$ \\
\hline $\begin{array}{l}\text { Mean reactivity }(\mathrm{SE}) \\
\left.\text { (percent change per kPa change in } \mathrm{EtCO}_{2}\right)\end{array}$ & $24(1.02)$ & $2.06(0.08)$ & $-0.63(0.09)$ & $1.44 \quad(0.1)$ \\
$\begin{array}{l}\text { Correlation coefficient between parameter } \\
\text { and } \mathrm{EtCO}_{2}\end{array}$ & 0.68 & 0.78 & -0.64 & 0.38 \\
\begin{tabular}{l} 
Significance level of correlation with $\mathrm{EtCO}_{2}$ \\
\hline
\end{tabular} & $p<0.001$ & $p<0.001$ & $p<0.001$ & $p<0.001$ \\
\hline
\end{tabular}

distance from source, giving a value for the rate of increase of attenuation with respect to the sourcedetector spacing. These measurements are converted into estimates of the product of absorption and scattering coefficients of the tissue according to the equation:

$$
\mu_{a} \times \mu_{s} \approx\left(\begin{array}{cc}
\delta A & 2 \\
\delta D & d
\end{array}\right)^{2}
$$

where

$\mu_{a}$ is the absorption coefficient,

$\mu_{s}$ is the scattering coefficient,

$A$ is the attenuation,

$d$ is the distance.

In vivo measurements have provided an algorithm that estimates the total tissue absorption coefficient for each wavelength of light. Using a regression model obtained from multiple regression analyses of known $\mathrm{Hb}$ and $\mathrm{HbO}_{2}$ concentration and absorption, the total absolute concentration of $\mathrm{Hb}$ and $\mathrm{HbO}_{2}$ for each absorption coefficient can be calculated, and mean cerebral hemoglobin oxygen saturation derived. ${ }^{37}$

Since the SRS uses photodiode detectors rather than photomultiplier tubes, the SRS is less sensitive to ambient light. However, the detector connections are of low voltage, and despite shielding are more susceptible to electrical interference. This feature is of potential practical concern for monitoring within the electrical hostility of the clinical setting. Nevertheless, we have incorporated the SRS into an intraoperative multimodality monitoring system to attempt direct validation against jugular bulb oxygen saturation $\left(\mathrm{SjO}_{2}\right)$ in patients undergoing routine cardiopulmonary bypass.

The results showed that the correlation between $\mathrm{SjO}_{2}$ measurements and SRS varied from patient to patient ( $r=0.08$ to 0.97$)$. A significant correlation was seen in 12 out of 24 patients (Figure 10). Overall, the range of changes seen with the SRS was not as great as those seen with $\mathrm{SjO}_{2}$ measurements, and SRS measurements tended to indicate a cerebral saturation that was 10 to $15 \%$ lower than those indicated by $\mathrm{SjO}_{2}$ measurements during the bypass period. $^{38}$
That SRS provided good correlation with $\mathrm{SjO}_{2}$ values in some patients is encouraging, since peripheral (i.e., scalp) hemoglobin saturation remained at 98 to $100 \%$ in all patients. However, we conclude that the variables discussed above, which are of equal importance in the application of SRS, have contributed to the variety of results obtained. A method to reliably exclude extracranial factors is clearly necessary before this technology can progress.

\section{CONCLUDING REMARKS}

Our experience with adult NIRS has shown promise, but has also reinforced previous concerns about variables that include differences in individual anatomy, siting of probes, and application techniques. These remain unresolved. However, using a highly controlled environment, detection of changes in intracranial cerebral chromophores is not doubted. For us, the most promising areas for adult NIRS application have been in head-injured patients, and in the assessment of $\mathrm{CO}_{2}$ reactivity. In both these clinical models, we are gaining confidence that cutaneous blood flow changes are small. This is not the case for patients with carotid artery disease, where extracranial to intracranial collateral

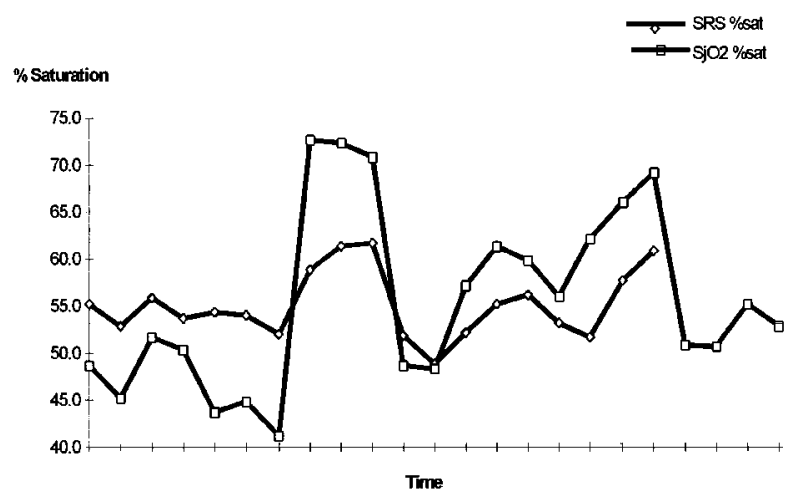

Fig. 10 Cerebral hemoglobin saturation values derived from jugular venous oximetry and spatially resolved spectroscopy in a patient undergoing hypothermic cardiopulmonary bypass. Good correlation was obtained throughout the procedure in this instance $(r=0.97)$, but SRS provided an estimate that was approximately 7 to $10 \%$ below that measured using $\mathrm{SjO}_{2}$. 
anastamoses are prominent, and where cutaneous blood flow changes can vary significantly in response to cerebral blood flow changes.

The development of reliable methods to monitor and subtract extracranial attenuation is the task that we face at present. Until this has been resolved, quantification of chromophore changes and attempts to calculate cerebral oxygen saturation may be premature. The addition of cutaneous laser flowmetry to our multimodality monitoring system has shown considerable promise in helping to identify the superficial component of the NIRS signal changes during $\mathrm{CE}$ and during $\mathrm{CO}_{2}$ reactivity assessments. These observations highlight the possibility that resolution of the extracranial from the intracranial compartment can be helped by paying attention to a physiological (rather than anatomical) means of signal segregation.

\section{APPENDIX}

Skin flow contributions to NIRS changes during $\mathrm{CO}_{2}$ reactivity testing were calculated as follows: During superficial temporal artery compression, the fall in skin flow $(L D F)$ was regressed against the associated fall in $\mathrm{HbO}_{2}$, and the slope of the regression (A) calculated (assuming a biological zero for $L D F$ of 0$)^{36}$

The skin contribution $\left[\Delta \mathrm{HbO}_{2(\text { skin })}\right]$ during $\mathrm{CO}_{2}$ changes was derived:

$$
\left[\Delta \mathrm{HbO}_{2(\mathrm{skin})}\right]=A\left[L D F_{\mathrm{CO}_{2}}\right] /\left[L D F_{\text {baseline }}\right],
$$

where $\left[L D F_{\mathrm{CO}_{2}}\right]$ is the $L D F$ value during hypercapnia, and $\left[L D F_{\text {baseline }}\right]$ the value during normocapnia.

Thus the skin influence

$$
=\left[\Delta \mathrm{HbO}_{2(\text { skin })}\right] /\left[\mathrm{HbO}_{2\left(\mathrm{CO}_{2}\right)}\right] 100 \% \text {, }
$$

and the corrected reactivity for $\mathrm{HbO}_{2}$

$$
=\text { observed reactivity of } \mathrm{HbO}_{2}-\left[\Delta \mathrm{HbO}_{2 \text { (skin) }}\right] \text {. }
$$

\section{REFERENCES}

1. K. H. Chan, J. D. Miller, N. M. Dearden, P. J. Andrews, and S. Midgley, "The effect of changes in cerebral perfusion pressure upon middle cerebral artery blood flow velocity and jugular bulb venous oxygen saturation after severe head injury," J. Neurosurg. 77, 55-61 (1992).

2. J. Cruz, "On-line monitoring of global cerebral hypoxia in acute brain injury. Relationship to intracranial hypertension," J. Neurosurg. 79, 228-233 (1993).

3. P. S. Gopinath, C. S. Robertson, C. F. Contant, R. K. Narayan, and R. G. Grossman, "Jugular venous desaturation and outcome after head injury," J. Neurol. Neurosurg. Psychiatry 57, 717-723 (1994).

4. A. I. R. Mass, W. Fleckenstein, D. A. De Jong and H. van Santbrink, "Monitoring cerebral oxygenation: experimental studies and preliminary clinical results of continuous monitoring of cerebrospinal fluid and brain tissue oxygen tension," Acta Neurochir. 59 (Suppl.) 50-57 (1993).

5. N. M. Dearden and S. Midgley, "Technical considerations in continuous jugular venous oxygen saturation measurement," Acta Neurochir. 59 (Suppl.) 91-97 (1993).
6. F. F. Jobsis, "Noninvasive, infrared monitoring of cerebral and myocardial oxygen sufficiency and circulation parameters," Science 198, 1264-1267 (1977).

7. D. T. Delpy, M. Cope, P. van der Zee, S. R. Arridge, S. Wray, and J. S. Wyatt, "Estimation of optical pathlength through tissues by direct time of flight measurement," Phys. Med. Biol. 33, 1433-1442 (1988).

8. P. van der Zee, M. Cope, S. R. Arridge, M. Essenpries, L. A. Potter, D. A. Edwards, J. S. Wyatt, D. C. McCormick, E. O. R. Reynolds, and D. T. Delpy, "Experimentally measured optical pathways for the adult head, calf and forearm of the newborn infant as a function of interoptode spacing," Adv. Exp. Med. Biol. 316, 143-153 (1992).

9. M. Cope and D. T. Delpy, "A system for long term measurement of cerebral blood and tissue oxygenation in newborn infants by near infrared transillumination," Med. Biol. Eng. Comp. 26, 289-294 (1988).

10. F. Faris, M. Thorniley, Y. Wickramasinghe, R. Houston, P. Rolfe, N. Livera, and A. Spencer, "Non-invasive in vivo near-infrared optical measurement of the penetration depth in the neonatal head," Clin. Phys. Physiol. Meas. 12, 353-358 (1991).

11. J. S. Wyatt, M. Cope, D. T. Delpy, S. Wray and E. O. R. Reynolds, "Quantification of cerebral oxygenation and hemodynamics in sick newborn infants by near infrared spectrophotometry," Lancet ii, 1063-1066 (1986).

12. J. S. Wyatt, M. Cope, D. T. Delpy, C. E. Richardson, A. D. Edwards, S. Wray, and E. O. R. Reynolds, "Quantification of cerebral blood volume in newborn infants by near infrared spectroscopy," J. Appl. Physiol. 68, 1086-1091 (1990).

13. A. D. Edwards, J. S. Wyatt, C. E. Richardson, D. T. Delpy, M. Cope, and E. O. R. Reynolds, "Cotside measurement of cerebral blood flow in ill newborn infants by near infrared spectroscopy," Lancet ii, 770-771 (1988).

14. A. D. Edwards, D. C. McCormick, S. C. Roth, C. Elwell, D. M. Peebles, M. Cope, J. S. Wyatt, D. T. Delpy, and E. O. R. Reynolds, "Cerebral hemodynamic effects of treatment with modified natural surfactant investigated by near infrared spectroscopy," Pediatr. Res. 32, 532-536 (1992).

15. M. Ferrari, D. De Marchis, I. Giannini, et al., “Cerebral blood volume and hemoglobin oxygen saturation monitoring in neonatal brain by near infrared spectroscopy," Adv. Exp. Med. Biol. 200, 203-212 (1986).

16. O. Pryds, G. Greisen, L. L. Skov, and B. Fris-Hansen, "Carbon dioxide related changes in cerebral blood volume and cerebral blood flow in mechanically ventilated preterm neonates: comparison of near infrared spectrophotometry and ${ }^{133}$ Xenon clearance," Pediatr. Res. 27, 445-459 (1993).

17. L. Skov, O. Pryds, and G. Greisen, "Estimating cerebral blood flow in newborn infants: comparison of near infrared spectroscopy and ${ }^{133}$ Xenon clearance," Pediatr. Res. 30, 570573 (1991).

18. L. Skov, O. Pryds, G. Grieisen, and H. Lou, "Estimation of cerebral venous saturation in newborn infants by near infrared spectroscopy," Pediat. Res. 33, 52-55 (1992).

19. C. E. Elwell, M. Cope, A. D. Edwards, J. S. Wyatt, E. O. R. Reynolds, and D. T. Delpy, "Measurement of cerebral blood flow in adult humans using near infrared spectroscopy methodology and possible errors," Adv. Exp. Med. Biol. 317, 235-245 (1992).

20. D. N. F. Harris, "Near infra-red spectroscopy," Editorial Anaesthesia 50, 1015-1016 (1995).

21. D. N. F. Harris and S. M. Bailey, "Near infrared spectroscopy in adults," Anaesthesia 48, 694-696 (1993).

22. T. J. Germon, N. M. Kane, A. R. Manara, and R. J. Nelson, "Near infrared spectroscopy in adults: effects of extracranial ischaemia and intracranial hypoxia on estimation of cerebral oxygenation," J. Anaesthesiol. 73, 503-506 (1994).

23. T. J. Germon, A. E. R. Young, A. R. Manara, and R. J. Nelson, "Extracerebral absorption of near infrared light influences the detection of increased cerebral oxygen monitored by near infrared spectroscopy," J. Neurol. Neurosurg. Psychiatry 58, 477-479 (1995).

24. C. E. Elwell, H. Owen-Reece, M. Cope, J. S. Wyatt, A. D. Edwards, D. T. Delpy, and E. O. R. Reynolds, "Measurement of changes in cerebral hemodynamics during inspira- 
tion and expiration using near infrared spectroscopy," Adv. Exp. Med. Biol. 345, 619-626 (1994).

25. M. Ferrari, E. Zannetta, I. Giannini, G. Sicher, C. Fieschi, and A. Carpi, "Effects of carotid compression test on regional cerebral blood volume, haemoglobin oxygen saturation and cytochrome-c-oxidase redox level in cerebrovascular patients," Adv. Exp. Med. Biol. 200, 213-222 (1986).

26. T. Kato, A. Kamei, S. Takashima, and T. Ozaki, "Human visual cortical function during photic stimulation monitoring by means of near infrared spectroscopy," J. Cereb. Blood Flow Metab. 13, 516-520 (1993).

27. Y. Hoshi and M. Tamura, "Detection of dynamic changes in cerebral oxygenation coupled to neuronal function during mental work in man," Neurosci. Lett. 150, 5-8 (1993).

28. P. J. Kirkpatrick, P. Smielewski, M. Czosnyka, D. A. Menon, and J. D. Pickard, "Near infrared spectroscopy in head injured patients," J. Neurosurg. (1995).

29. P. Smielewski, P. J. Kirkpatrick, P. Mihas, J. D. Pickard, and M. Czosnyka, "Can cerebrovascular reactivity be measured using near infrared spectroscopy?," Stroke 26, 2285-2292 (1995).

30. P. J. Kirkpatrick, M. Czosnyka, and J. Pickard, "Multimodality monitoring in neurointensive care," (Editorial) J. Neurol. Neurosurg. Psychiatry 60, 131-139 (1996).

31. M. Czosnyka, H. Whitehouse, P. Smielewski, P. J. Kirkpatrick, and J. D. Pickard, "Computer supported multimodal bed-side monitoring in neurointensive care," Int. J. Clin. Monitor. Comput. 11, 223-232 (1994).

32. P. J. Kirkpatrick, P. Smielewski, P. W. Whitfield, D. A.
Menon, and J. D. Pickard, "An observational study of near infrared spectroscopy during carotid endarterectomy," J. Neurosurg. 82, 756-763 (1995).

33. P. J. Kirkpatrick, P. Smielewski, D. K. Menon, and M. Czosnyka, "Quantification of cerebral haemodynamic responses following internal carotid artery clamping using near infrared spectroscopy," J. Neurol. Neurosurg. Psychiatry (in press) (1996).

34. J. M. K. Lam, P. J. Kirkpatrick, P. Al-Rawi, P. Smielewski, and J. D. Pickard, "Internal and external carotid contribution to near infrared spectroscopy (NIRS) changes during carotid endarterectomy," J. Neurol. Neurosurg. Psychiatry (in press) (1996).

35. P. Smielewski, P. J. Kirkpatrick, M. Czosnyka, and J. D. Pickard, "Reliability of near infrared spectroscopy (NIRS) in the assessment of $\mathrm{CO}_{2}$ reactivity in patients with cerebrovascular disease," J. Neurol. Neurosurg. Psychiatry (in press) (1996).

36. H. K. Richards, M. Czosnyka, P. Kirkpatrick, and J. D. Pickard, "Estimation of laser doppler flux biological zero using basilar artery flow velocity in the rabbit," Am. J. Physiol. 268, H213-H217 (1995).

37. S. Matcher, P. J. Kirkpatrick, Nahid, and D. T. Delpy, "Absolute quantification methods in tissue near infrared spectroscopy," Proc. SPIE (in press) (1996).

38. P. Al-Rawi, P. Smielewski, Gosh, et al., "Calibration of spatially resolved spectroscopy during cardiopulmonary bypass," J. Neurol. Neurosurg. Psychiatry (in press) (1996). 